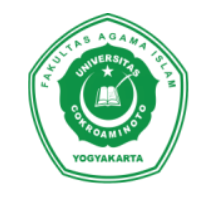

Ulumuddin: Jurnal Ilmu-ilmu Keislaman

P-ISSN: 1907-2333 E-ISSN: 2685-9211

https://jurnal.ucy.ac.id/index.php/agama_islam

Volume 10 Nomor 2, Desember 2020, h. 103 - 116

\title{
PERBEDAAN INTOLERANSI POLITIK JAMAAH NAHDLATUL WATHAN TERHADAP JAMAAH AHMADIYAH DITINJAU DARI GENDER
}

Tutut Chusniyah ${ }^{*}$ ), Fattah Hidayat ${ }^{2)}$, Maulanal Kirom Firdaus3)

1)tutut.chusniyah.fppsi@um.ac.id, 2) fatah.hidayat.fppsi@um.ac.id, 3)maulanalkiromf@gmail.com

123) Universitas Negeri Malang

* Penulis Koresponden

\begin{tabular}{|l|l|l|}
\hline Diajukan: 12-11-2020 & Diterima: 23-11-2020 & Diterbitkan: 29-12-2020
\end{tabular}

\begin{abstract}
Political intolerance in this study is the unwillingness of a person or group to accept the actions, talks and views of the Ahmadiyya congregation which include disrespecting the civil rights of others, disrespecting freedom of expression, and disrespecting the beliefs of others. Gender roles are roles played by women and men in accordance with the status of the environment, culture and society structure. The aim of research to find out the differences of political intolerance in the congregation of the Ahmadiyya Muslim Nahdlatul Wathan Pancor, Lombok if the terms of gender. This study has 1 dependent variable, namely political intolerance with 1 independent variable, namely gender. The subjects of this study were 90 members of the Nahdlatul Wathan Jamaah, consisting of 45 men and 45 women. The research instrument used was the political intolerance scale $(\alpha=0.837)$. The results showed that there was no difference in political intolerance between male and female Nahdlatul Wathan congregations against the Pancor Ahmadiyah Community, East Lombok with t count $<$ table $(-0.362<1.987)$ and $P$ value (0.718> 0.05). Recommendations for future research to examine other variables that influence political intolerance, such as authoritarian variables, contacts or relationships, education, government policies and ethnic diversity.
\end{abstract}

Keywords: Political Intolerance, Jamaah Nahdlatul Wathan, Jamaah Ahmadiyah, Gender

\begin{abstract}
Abstrak. Intoleransi politik dalam penelitian ini adalah ketidaksediaan seseorang atau kelompok untuk menerima tindakan, pembicaraan dan pandangan jamaah Ahmadiyah yang meliputi tidak menghormati hak-hak sipil orang lain, tidak menghormati kebebasan berekspresi, dan tidak menghormati keyakinan orang lain. Peran gender merupakan peran yang dilakukan perempuan dan laki-laki sesuai dengan status lingkungan, budaya dan struktur masyarakat. Tujuan penelitian ini untuk mengetahui perbedaan intoleransi politik pada jamaah Nahdlatul Wathan terhadap Jamaah Ahmadiyah Pancor, Lombok Timur jika ditinjau dari gender. Penelitian ini memiliki 1 variabel terikat, yaitu intoleransi politik dengan 1 variabel bebas yaitu gender. Subjek penelitian ini adalah Jamaah
\end{abstract}


Nahdlatul Wathan sebanyak 90 orang dengan rincian 45 laki-laki dan 45 perempuan. Instrumen penelitian yang digunakan adalah skala intoleransi politik $(\alpha=0,837)$. Hasil penelitian menunjukkan bahwa tidak ada perbedaan intoleransi politik pada jamaah Nahdlatul Wathan laki-laki maupun perempuan terhadap Jamaah Ahmadiyah Pancor, Lombok Timur dengan nilai t hitung $<\mathrm{t}$ tabel $(-0.362<1.987)$ dan $\mathrm{P}$ value $(0,718>0.05)$. Rekomendasi bagi penelitian selanjutnya agar dapat menguji variabel lain yang mempengaruhi intoleransi politik, seperti variabel otoritarian, kontak atau hubungan, pendidikan, kebijakan pemerintah dan keragaman etnis.

Kata kunci: Intoleransi Politik, Jamaah Nahdlatul Wathan, Jamaah Ahmadiyah, Gender

\section{A. Pendahuluan}

Mayoritas masyarakat Lombok merupakan Jamaah Nahdlatul Wathan (selanjutnya disebut NW), yaitu organisasi sosial keagamaan lokal yang bergerak dalam bidang pendidikan, sosial dan dakwah. NW terbentuk pada tahun 1953 di Kelurahan Pancor, Lombok Timur. Selain jamaah NW, Pulau Lombok juga menjadi salah satu daerah penyebaran Jamaah Ahmadiyah. Menurut Kepala Kanwil Kemenag NTB, jumlah Jamaah Ahmadiyah di Lombok sebanyak 180 KK. ${ }^{1}$

Penolakan terhadap Jamaah Ahmadiyah di Lombok terjadi pertama kali pada tahun 1999, yaitu pembakaran masjid Ahmadiyah di Bayan. ${ }^{2}$ Selanjutnya pada tahun 2001, terjadi penyerangan terhadap Jamaah Ahmadiyah di Pancor, Lombok Timur dan pada tahun 2006, terjadi pembakaran rumah di Ketapang.3 Pada tahun 2018, terjadi perusakan 6 (enam) dan 24 Jamaah Ahmadiyah dievakuasi ke Kantor Polres Lombok Timur,4 dan 35 KK atau 155 anggota Jamaah Ahmadiyah

1 AntaraNews, "Isu Diserang, Warga Ahmadiyah Aangkut Harta Benda ke Pengungsian,” November 2010.

2 Sigit Purnomo, "Nasib Ahmadiyah, Terlantar di Negeri Sendiri," BBC News, last modified 2013, https://www.bbc.com/indonesia/berita_indonesia/ 2013/o8/ 130802_ahmadiyah_lombok.

3 Ahmad Muzakky Al-Hasan, "Terusir, Penganut Ahmadiyah Lombok Hidup Menetap di Pengungsian," last modified 2015, https://www.rappler.com/world/asiapacific/mengunjungi-pengungsi-jamaah-ahmadiyah-di-lombok.

4 R. Bonasir, "Kenapa Ahmadiyah dianggap bukan Islam: Fakta dan Kontroversinya," BBC Indonesia, 2018. 
masih mengungsi di Asrama Transito Kota Mataram dan 5 KK di eks RSUD Praya, Lombok Tengah. 5

Pada tahun 2009, Dinas Sosial Kependudukan dan Catatan Sipil NTB telah berupaya untuk memindahkan jamaah Ahmadiyah ke berbagai lokasi agar dapat membaur dengan masyarakat lain ${ }^{6}$, namun upaya itu gagal karena masyarakat menolak mereka. Dengan demikian, kekerasan dan penolakan yang dialami oleh Jamaah Ahmadiyah di Lombok dan pemulihan hak-hak mereka atas kebebasan beragama atau berkeyakinan sampai saat ini belum terselesaikan.

Intoleransi politik terhadap jamaah Ahmadiyah terjadi karena keyakinan yang dianut berbeda dengan keyakinan masyarakat sekitar. Sesuai penjelasan Akindele, Olaopa, \& Salaam,7 bahwa saat individu atau kelompok tidak menerima tindakan, ucapan atau pandangan individu atau kelompok lain yang berbeda, termasuk kurangnya rasa hormat, penerimaan dan akomodasi terhadap hak dan kebebasan orang lain terjadilah intoleransi politik. ${ }^{8}$

Intoleransi politik didefinisikan sebagai ketidaksediaan seseorang atau kelompok untuk menerima tindakan, pembicaraan dan pandangan individu maupun kelompok lain yang berbeda. Intoleransi memiliki potensi perilaku yang lebih kuat dibanding toleransi.9 Individu lebih berintensi untuk bertindak secara politik atas sikap intoleran mereka daripada sikap toleran. ${ }^{10}$ Intoleransi politik memunculkan kekerasan dan intimidasi sebagai reaksi alami orang-orang yang melakukannya. ${ }^{11}$

5 Thomas Harming Suwarta, "Sudah 11 Tahun, Pemulihan Hak Jemaah Ahmadiyah di NTB Belum Terselesaikan," Media Indonesia, 2018.

${ }^{6}$ Kompas, "Warga NTB Masih Menolak 130 Warga JAI," 2009.

7 S.T. Akindele, O.R. Olaopa, dan N.F. Salaam, "Political Intolerance As A Clog In The Wheel Of Democratic Governance: The Way Forward," African Journal of Political Science and International Relations 3, no. 8 (2009): 365-379.

8 Ibid.

9 J. L. Gibson, "Enigmas of intolerance: Fifty years after Stouffer's Communism, Conformity, and Civil Liberties," Perspectives on Politics 4, no. 1 (2006): 21-34.

10 G. E. Marcus et al., With Malice toward Some: How People Make Civil Liberties Judgments (New York: Cambridge University Press, 1995).

${ }_{11}$ Akindele, Olaopa, dan Salaam, "Political Intolerance" 
Padahal Sebastian Castellio (tahun 1515-1563) sebenarnya secara terbuka telah mendorong toleransi agama dan politik. ${ }^{12}$ Istilah toleransi saat ini tidak hanya diperuntukkan bagi toleransi keragaman agama saja, melainkan juga diterapkan pada keragaman orientasi politik, etnis atau ras, masalah gender, homoseksualitas, eutanasia dan aborsi.13 Toleransi politik menurut Gibson, ${ }^{14}$ menyangkut dukungan terhadap kebebasan sipil dari kelompok yang tidak disukai atau tidak populer, sedangkan intoleransi merupakan kebalikan dari toleransi. Toleransi memungkinkan minoritas dapat mengekspresikan identitas budaya dan agama mereka, memberikan akses ke sumber daya dan hak, serta melindungi dari kekerasan. ${ }^{15}$

Faktor-faktor yang menyebabkan intoleransi politik meliputi faktor individual seperti kepribadian otoritarianisme, ${ }^{16}$ persepsi ancaman, ${ }^{17}$ kontak atau hubungan, ${ }^{18}$ pendidikan, ${ }^{19}$ demografi seperti status sosioekonomi, ${ }^{20}$ agama, ${ }^{21}$ gender, ${ }^{22}$ dan faktor kontekstual seperti sistem

12 J. Goudsblom, "Amsterdam: Amsterdam University Press," in Macht en Verantwoordelijkheid. Essays Voor Kees Schuyt. (Amsterdam: Amsterdam University Press, 2007), 43-53.

13 Marjoka Van Doorn, "The Nature of Tolerance and The Social Circumstances in Which it Emerges," Current Sociology 62, no. 6 (2014): 905-927.

14 Gibson, "Enigmas of intolerance: Fifty years after Stouffer's Communism, Conformity, and Civil Liberties."

15 T. M. Scanlon, The Difficulty ofTolerance: Essays in Political Philosophy (Cambridge New York: Cambridge University Press, 2003).

16 J. Duckitt dan C. G. Sibley, "Personality, Ideology, Prejudice, and Politics: A Dual-process Motivational Model,” Journal of Personality and Social Psychology 78, no. 6 (2010): 1861-1893.

17 Angga Yuni Mantara, Tutut Chusniyah, dan Muh. Amin Arqi, "Menjadi Kelompok Minoritas dalam Mayoritas: Persepsi Ancaman, Orientasi Dominasi Sosial dan Intoleransi Terhadap Jamaah Ahmadiyah," in International Conference on Islam And Civilizations (ICIC) (Jakarta: Universitas Negeri Jakarta, 2019); Muh. Amin Arqi, Tutut Chusniyah, dan Aji Bagus Priyambodo, "Persepsi Ancaman sebagai Prediktor Intoleransi Politik terhadap Jamaah Ahmadiyah pada Jamaah Nahdlatul Wathan Pancor Lombok Timur," in Prosiding Seminar Nasional Psikologi Indigenous Indonesia 2016 "Kebhinekaan dan Masa Depan Indonesia: Peran Ilmu Sosial dalam Masyarakat" (Malang: Universitas Negeri Malang, 2016).

18 Yasushi Hazama, "Determinants of Political Tolerance: A Literature Review," Institute of Developing Economies (IDE) 288 (2011): 1-14.

19 S. Keuzenkamp, "Acceptatie van Homoseksualiteit in Nederland," in Internationale Vergelijking, Ontwikkelingen en Actuele Situatie (Den Haag: Sociaal en Cultureel Planbureau, 2011).

20 A. Katnik, "Religion, Social Class, and Political Tolerance: A Cross-National Analysis," International Journal of Sociology 32, no. 1 (2002): 14-28.

${ }^{21}$ B. A. Yeşilada dan P. Noordijk, "Changing Values in Turkey: Religiosity and Tolerance in Comparative Perspective," Turkish Studies 11, no. 1 (2010): 9-27; Taufik 


\section{Perbedaan Intoleransi Politik Jamaah Nahdlatul Wathan}

Terhadap Jamaah Ahmadiyah Ditinjau Dari Gender

pemerintahan/kebijakan pemerintah, internalisasi norma demokratik. ${ }^{23}$ Misalnya remaja Belanda yang menjunjung tinggi nilai keragaman budaya cenderung toleran terhadap praktik Muslim. ${ }^{24}$

M. Gieling, J. Thijs, dan M. Verkuyten menyebutkan bahwa indikator toleransi politik, ${ }^{25}$ yaitu (a) menghormati kebebasan dan kemerdekaan orang lain dalam berpendapat, berbicara dan bertindak, (b) kebebasan berekspresi, dan (c) menghormati keyakinan orang lain. Dimensi intoleransi politik dalam penelitian ini didasarkan pada pendapat Cogen dan Almagor yang merupakan kebalikan dari toleransi politik; yaitu tidak menghormati hak-hak sipil orang, tidak menghormati kebebasan berekspresi orang lain, dan tidak menghormati keyakinan orang lain.

Sejauh ini, intoleransi politik merupakan fenomena yang paling banyak diteliti dalam ilmu politik modern, ${ }^{26}$ dan dalam hubungan antar kelompok juga sangat bermanfaat bagi perkembangan ilmu psikologi sosial. ${ }^{27}$ Intoleransi politik merupakan masalah yang sangat penting, karena menurut Immanuel, ${ }^{28}$ orang-orang yang melakukan intoleransi politik secara alami bereaksi dengan melakukan kekerasan dan intimidasi. Akan tetapi di sisi lain, ${ }^{29}$ menyampaikan bahwa intoleransi politik memunculkan konformitas budaya. Dengan demikian, semakin buruk dan

Nugroho, "Pendidikan Ideologi Al-Islam Pondok Pesantren Tenggulun Solokuro Lamongan," Ulumuddin : Jurnal Ilmu-ilmu Keislaman 9, no. 2 (2019): 97-112.

${ }_{22}$ Maykel Verkuyten dan Luuk Slooter, "Muslim and Non-Muslim Adolescents' Reasoning About Freedom of Speech and Minority Rights," Child Development 79, no. 3 (2008): 514-528.

${ }^{23}$ L. Hagendoorn dan W. H. Poppe, "Consistency of Tolerance, Public Opinion on Immigrants in the Netherlands at The Turn of The Millennium," Politics, Culture and Socialization 2, no. 4 (2012): 367-387; Umi Musaropah, "Pendidikan Kebangsaan Dalam Pesantren Perspektif Abdul Wahid Hasyim," Ulumuddin: Jurnal Ilmu-ilmu Keislaman 9, no. 1 (2019): 1-22.

${ }^{24}$ M. Gieling, J. Thijs, dan M. Verkuyten, "Voluntary and involuntary Immigrants and Adolescents' Endorsement of Multiculturalism," International Journal of Intercultural Relations 35, no. 2 (2011): 259-267.

${ }_{25}$ Raphael Cohen-Almagor, The Scope of Tolerance: Studies on the Costs of Free Expression and Freedom of The Press (London and New York: Routledge, 2006).

${ }^{26}$ Gibson, "Enigmas of"

27 Amélie Mummendey dan Michael Wenzel, "Social Discrimination and Tolerance in Intergroup Relations: Reactions to Intergroup Difference," Personality and Social Psychology Review 3, no. 2 (1999): 158-174. Nation."

${ }_{28}$ F. W. Immanuel, "Namibia: Political Tolerance Towards One Namibia, One

29 Gibson, "Enigmas of" 
merugikannya efek intoleransi politik membuat masyarakat berpotensi untuk saling menekan satu sama lain agar conform.

Rueckert \& Naybar,30 juga menunjukkan bahwa wanita lebih toleran daripada pria, karena wanita lebih empati dalam konteks hubungan antar kelompok. ${ }^{31}$ Wanita juga lebih memiliki rasa takut, sedih, rasa bersalah serta rasa malu dibanding Laki-laki. ${ }^{22}$ Selain itu, laki-laki lebih mudah terlibat dengan perilaku agresif dibanding wanita karena secara biologis berpotensi lebih tinggi tingkat agresivitasnya.33 Penelitian Lozano dan Etxebarria juga menunjukkan bahwa anak perempuan mendapat skor toleransi lebih tinggi daripada anak laki-laki pada semua subskalanya. 34

Hasil penelitian yang berbeda ditunjukkan dalam penelitian Marcus.35 bahwa wanita secara politik terbukti lebih tidak toleran dibanding pria. Temuan penelitian Verkuyten, ${ }^{36}$ dan Verkuyten \& Slooter,37 juga menunjukkan bahwa wanita kurang toleran terhadap praktik-praktik (baik agama atau sekuler) yang tidak menguntungkan wanita. Berdasarkan beberapa penelitian di atas menunjukkan adanya perbedaan temuan yang bertentangan, oleh karena itu penelitian ini ingin melihat apakah ada perbedaan gender dalam intoleransi politik dalam konteks hubungan antar kelompok Islam yaitu Jamaah Nahdlatul Wathan terhadap Jamaah Ahmadiyah di Lombok. Penelitian sebelumnya terhadap

3o Linda Rueckert dan Nicolette Naybar, "Gender Differences in Empathy: The Role of The Right Hemisphere," Brain and Cognitive 67 (2008): 162-167.

31 N. L. Cundiff dan M. Komarraju, "Gender Differences in Ethnocultural Empathy and Attitudes toward Men and Women in Authority," Journal of Leadership \& Organizational Studies 15, no. 1 (2008): 5-15.

32 Terri D. Fisher, Clive M. Davis, dan William L. Yarbe, Handbook of SexualityRelated Measures (United Kingdom: Routledge, 2013).

33 Itziar Etxebarria Bilbao et al., "Diferencias De Género en Emociones y En Conducta Social En La Edad Escolar," Journal for the Study of Education and Development, Infancia y Aprendizaje 26, no. 2 (2003): 147-162.

34 Ana Ma Lozano dan Itziar Etxebarria, "Tolerance of Diversity in Adolescents and Its Relationship with Self-Esteem, Empathy and The Concept of Human Being," Journal for the Study of Education and Development 30, no. 1 (2007): 109-129.

35 George E. Marcus, "Ethnography in/of the world system: The emergence of multi-sited ethnography.," Annual Review of Anthropology 24 (1995): 95-117.

36 Maykel Verkuyten, "Social Psychology and Multiculturalism," Social and Personality Psychology Compass 1 (2007): 280-297.

37 M. Verkuyten dan L. Slooter, "Muslim and Non-Muslim Adolescents' Reasoning about Freedom of Speech and Minority Rights," Child Development 79, no. 3 (2008): 514-528. 
Jamaah Nahdlatul Wathan menunjukkan bahwa persepsi ancaman,38 Right-Wing Authoritarianism (RWA).39 persepsi ancaman dan Social Dominance Orientation (SDO),40 mempengaruhi intoleransi politik.

\section{B. Metode}

Penelitian ini menggunakan pendekatan komparatif, dimana peneliti membandingkan dua kelompok berbeda yang bertujuan untuk mengetahui perbedaan intoleransi politik ditinjau dari gender. Variabel bebas $(\mathrm{X})$ adalah peran gender dan variabel terikat $(\mathrm{Y})$ adalah intoleransi politik. Berikut akan dijelaskan populasi dan sampel, instrumen penelitian, dan analisis data.

Populasi dalam penelitian adalah Jamaah Nahdlatul Wathan yang tinggal di Bermi, Kelurahan Pancor, Kabupaten Lombok Timur, Nusa Tenggara Barat. Berdasarkan pertimbangan bahwa Bermi merupakan basis Nahdlatul Wathan, maka peneliti berasumsi bahwa semua penduduk Lingkungan Bermi merupakan Jamaah Nahdlatul Wathan berjumlah 1383 orang. Teknik pengambilan sampel yang digunakan dalam penelitian berupa simple random sampling dengan metode ganjil dan genap pada rumah-rumah penduduk. Subyek yang digunakan sebagai sampel penelitian sebanyak 90 orang dengan rincian 45 laki-laki dan 45 perempuan.

Instrumen penelitian yang digunakan adalah skala intoleransi politik terhadap jamaah Ahmadiyah berjumlah 17 aitem yang disusun peneliti berdasarkan teori Cohen-Almagor, ${ }^{41}$ yang meliputi tiga indikator yaitu; 1) tidak menghormati hak-hak sipil orang (6 aitem), 2) tidak menghormati kebebasan berekspresi orang lain (6 aitem), dan 3) tidak menghormati keyakinan orang lain (5 aitem). Uji coba instrumen penelitian dilakukan untuk mengetahui validitas dan reliabilitas skala serta melakukan seleksi aitem penelitian. Validitas instrumen dilakukan dengan pengujian validitas konten dengan menyusun pertanyaan sesuai

${ }^{38}$ Arqi, Chusniyah, dan Priyambodo, "Persepsi Ancaman."

39 Jarret T. Crawford dan Jane M. Pilanski, "The Differential Effects of Right-Wing Authoritarianism and Social Dominance Orientation on Political Intolerance," Political Psychology 35, no. 4 (2014): 557-576.

40 Mantara, Chusniyah, dan Arqi, "Menjadi Kelompok"

${ }^{41}$ Cohen-Almagor, The Scope of 
dengan indikator dan deskripsi variabel. Selanjutnya dilakukan analisis item-total dan diperoleh 15 aitem valid dan 2 aitem tidak valid dengan nilai validitas 0,00-0,oo. Sedangkan reabilitas dalam penelitian ini didapatkan koefisien reliabilitas Alpha Cronbach 0.837.

\section{Hasil}

Uji asumsi dilakukan sebelum melakukan uji hipotesis, yang terdiri uji normalitas dan uji homogenitas. Uji normalitas menggunakan teknik analisis Kolmogorov-Smirnov dengan memperhatikan nilai a > 0,05. Uji homogenitas dengan taraf signifikansi > 0.05, Selanjutnya uji hipotesis dilakukan dengan menggunakan analisis independen sample t-test untuk membedakan intoleransi politik pada Jamaah Nahdlatul Wathan terhadap Jamaah Ahmadiyah Pancor, Lombok Timur ditinjau dari gender. Uji t dilakukan dengan memperhatikan tingkat signifikasi (a) 0,05, bila signifikansi > 0,05, maka $\mathrm{H}_{\mathrm{o}}$ diterima ditolak dan sebaliknya.

Karakteristik responden didasarkan atas penggolongan jenis kelamin, usia, pendidikan dan pekerjaan, dapat dilihat pada Tabel 1 berikut:

Tabel 1. Karakteristik Responden Jenis Kelamin

\begin{tabular}{llcc}
\hline \multirow{2}{*}{ Karakteristik } & & \multicolumn{2}{c}{ Frekunsi } \\
\cline { 3 - 4 } & & Jumlah & Prosentasi \\
\hline Gender & Laki-laki & 45 & $50 \%$ \\
\multirow{2}{*}{ Jumlah } & Perempuan & 45 & $50 \%$ \\
& & 90 & $100 \%$ \\
Usia Laki-Laki & & & \\
& $20-30$ & 23 & $51 \%$ \\
Usia Perempuan & $31-40$ & 11 & $24,5 \%$ \\
& $41-50$ & 11 & $24,5 \%$ \\
Jumlah & $20-30$ & 23 & $51 \%$ \\
& $31-40$ & 17 & $38 \%$ \\
& $41-50$ & 5 & $11 \%$ \\
\end{tabular}

Selanjutnya hasil uji normalitas dengan menggunakan Kolmogorov Smirnov Test menunjukkan bahwa sebaran data dari setiap variabel dalam penelitian adalah normal karena nilai Asymp. Sig (p) lebih besar dari o,05. Berdasarkan uji homogenitas yang dilakukan pada variabel variabel intoleransi politik, diketahui bahwa nilai signifikansi lebih besar dari 0.05, yaitu $0,323>0.05$. Dengan demikian, dapat disimpulkan bahwa data 
kelompok laki-laki dan perempuan memiliki varians yang homogen. Berikut tabel uji asumsi;

Tabel 2. Hasil Uji Asumsi

\begin{tabular}{lllcl}
\hline \multicolumn{1}{c}{ Uji Asumsi } & Gender & Nilai F & Signifikansi & Kesimpulan \\
\hline \multirow{2}{*}{ Normalitas } & Laki-laki & - & 0,076 & Normal \\
& Perempuan & - & 0,200 & Normal \\
\hline \multirow{2}{*}{ Homogenitas } & - & 0,987 & 0,323 & Homogen \\
\hline
\end{tabular}

Selanjutnya untuk menguji hipotesis kerja yaitu tidak ada perbedaan perbedaan intoleransi politik Jamaah Nahdlatul Wathan terhadap Jamaah Ahmadiyah Pancor, Lombok Timur ditinjau dari gender dianalisis dengan menggunakan independent t-test dengan bantuan SPSS Statistic 20.o for Windows. Berikut hasil uji hipotesis;

Tabel 3. Hasil Uji Hipotesis

\begin{tabular}{lcrrrrrr}
\hline \multirow{3}{*}{ Intoleransi } & \multirow{2}{*}{$\mathrm{t}$} & $\mathrm{df}$ & $\begin{array}{c}\text { Sig (2- } \\
\text { tailed) }\end{array}$ & $\begin{array}{c}\text { Mean } \\
\text { Difference }\end{array}$ & \multirow{2}{*}{$\begin{array}{c}\text { Std. Error } \\
\text { Difference }\end{array}$} & \multicolumn{2}{c}{$\begin{array}{c}\text { 95\% Confidence } \\
\text { Interval }\end{array}$} \\
\cline { 2 - 6 } & & & & & & Lower & Upper \\
\hline
\end{tabular}

Berdasarkan analisis data, maka dapat didapat $\mathrm{P}$ value $(0,174>$ 0.05) sehingga Ha ditolak, artinya tidak ada perbedaan intoleransi politik Jamaah Nahdlatul Wathan terhadap Jamaah Ahmadiyah Pancor, Lombok Timur ditinjau dari gender. Selanjutnya dilakukan uji beda setiap subskala ditinjau dari gender, dengan hasil sebagai berikut; 1) pada sub skala indikator tidak menghargai hak-hak sipil, dikarenakan nilai signifikansi atau $\mathrm{P}$ value (0,25 > 0,05) maka disimpulkan tidak ada perbedaan intoleransi politik antara kelompok laki-laki dan perempuan, 2) pada sub skala indikator tidak menghormati kebebasan berekspresi orang lain, dikarenakan nilai signifikansi atau $\mathrm{P}$ value (0,314 > 0,05) maka ditarik kesimpulan bahwa tidak ada perbedaan antara kelompok laki-laki dan perempuan, dan 3) pada sub skala indikator tidak menghormati keyakinan orang lain, dikarenakan nilai signifikansi atau $\mathrm{P}$ value $(0,025<0,05)$ sehingga dapat ditarik kesimpulan bahwa ada perbedaan antara kelompok laki-laki dan perempuan.

\section{Pembahasan}

Dari hasil analisis uji hipotesis diketahui bahwa tidak ada perbedaan intoleransi politik Jamaah Nahdlatul Wathan terhadap Jamaah 
Ahmadiyah ditinjau dari gender. Hasil penelitian ini berbeda dengan penelitian-penelitian sebelumnya seperti penelitian Cundiff dan Komarraju,42 Lozano dan Etxebarria,43 Marcus, dkk.,44 Rueckert dan Naybar,45 bahwa laki-laki lebih intoleran dibanding perempuan, dan penelitian,46 yang menemukan bahwa perempuan lebih intoleran dibanding laki-laki.

Selanjutnya hasil uji beda setiap sub-skala ditinjau dari gender, menunjukkan tidak ada perbedaan intoleransi politik antara kelompok laki-laki dan perempuan pada sub-skala tidak menghargai hak-hak sipil dan sub-skala indikator tidak menghormati kebebasan berekspresi orang lain. Sedang pada sub-skala tidak menghormati keyakinan orang lain, disimpulkan bahwa ada perbedaan antara kelompok laki-laki dan perempuan. Hasil penelitian ini juga berbeda dengan penelitian yang dilakukan oleh Lozano dan Etxebarria,47 bahwa pada semua sub-skala toleransi politik, perempuan mendapat skor lebih tinggi daripada laki-laki.

Perbedaan hasil penelitian, disebabkan karena intoleransi politik merupakan fenomena antar kelompok, bukan masalah individual. 48 (In)toleransi terjadi saat terjadi kontroversi dalam keyakinan dan konflik dalam hubungan antar kelompok. Individu mentoleransi orang lain tergantung keanggotaannya dalam kelompok, saat kelompoknya bersikap intoleran terhadap kelompok lain, maka apapun gendernya begitu juga mereka akan bersikap.

Selanjutnya melihat sejarah konflik jamaah Nahdatul Wathan dengan Jamaah Ahmadiyah di kelurahan Pancor semakin meruncing setelah diterbitkannya Surat Keputusan Bersama (SKB) Menteri.49 Selain itu, Majelis Ulama Indonesia (MUI) dan tokoh agama setempat sering

42 Cundiff dan Komarraju, "Gender Differences"

43 Lozano dan Etxebarria, "Tolerance of"

44 Marcus et al., With Malice

45 Rueckert dan Naybar, "Gender Differences"

46 Verkuyten dan Slooter, "Muslim and"; Verkuyten, "Social Psychology"; Keuzenkamp, "Acceptatie van"

47 Lozano dan Etxebarria, "Tolerance of"

48 Doorn, "The Nature of"

49 Purnomo, "Nasib Ahmadiyah" 
menyatakan bahwa ajaran Ahmadiyah adalah ajaran yang sesat.50 SKB Menteri, pandangan MUI dan pernyataan tokoh agama setempat sebagai pandangan pihak yang memiliki otoritas yang menyudutkan jamaah Ahmadiyah menjadi salah satu faktor yang mempengaruhi intoleransi politik, karena pandangan orang yang memiliki otoritas dalam kelompoknya dianggap sebagai sesuatu yang harus dituruti. Demikianlah yang dinyatakan oleh Rukambe dalam Akindele dkk .51

Selanjutnya, penelitian ini juga menunjukkan bahwa (in)toleransi bergantung pada informasi tentang siapa, apa, dan kapan orang diminta untuk mentolerir perbedaan pendapat, keyakinan atau praktik. ${ }^{2}$ Isu moral cenderung menghasilkan penolakan yang lebih besar, terlepas dari emosi moral dan konteksnya.53 Dalam konteks intoleransi Jamaah Nahdlatul Wathan terhadap Jamaah Ahmadiyah, faktor demografi yaitu gender tidak berperan. Saat otoritas agama menolak pandangan, keyakinan dan praktik jamaah Ahmadiyah sehingga isu moral mengedepan, maka anggota jamaah Nahdhatul Wathan baik laki-laki maupun perempuan menjadi intoleran terhadap jamaah Ahmadiyah.

\section{E. Kesimpulan}

Penelitian menyimpulkan bahwa tidak ada perbedaan intoleransi politik pada Jamaah Nahdlatul Wathan terhadap Jamaah Ahmadiyah Pancor, Lombok Timur antara jenis kelamin perempuan dan laki-laki. Selanjutnya hasil uji beda setiap sub-skala ditinjau dari gender, menunjukkan tidak ada perbedaan intoleransi politik antara kelompok laki-laki dan perempuan pada sub-skala tidak menghargai hak-hak sipil dan sub-skala indikator tidak menghormati kebebasan berekspresi orang lain. Sedangkan pada sub-skala tidak menghormati keyakinan orang lain, disimpulkan bahwa ada perbedaan antara kelompok laki-laki dan perempuan. Perbedaan hasil penelitian, disebabkan karena intoleransi

5o Ibid.

${ }^{11}$ Akindele, Olaopa, dan Salaam, "Political Intolerance"

$5^{2}$ Michael Bang Petersen et al., "Freedom for All? The Strength and Limits of Political Tolerance," British Journal of Political Science 41, no. 3 (2011): 581-597.

53 J. C. Wright, J. Cullum, dan N. Schwab, "The Cognitive and Affective Dimensions of Moral Conviction: Implications for Attitudinal and Behavioral Measures of Interpersonal Tolerance," Personality and Social Psychology Bulletin 34, no. 11 (2008): $1461-1476$. 
politik merupakan fenomena antar kelompok, bukan masalah individual. Intoleransi terjadi saat terjadi kontroversi dalam keyakinan dan konflik dalam hubungan antar kelompok. Individu mentoleransi orang lain tergantung keanggotaannya dalam kelompok, saat kelompoknya bersikap intoleran terhadap kelompok lain, maka apapun gendernya begitu juga mereka akan bersikap.

\section{Referensi}

Akindele, S.T., O.R. Olaopa, dan N.F. Salaam. "Political Intolerance As A Clog In The Wheel Of Democratic Governance: The Way Forward." African Journal of Political Science and International Relations 3, no. 8 (2009): 365-379.

Al-Hasan, Ahmad Muzakky. "Terusir, Penganut Ahmadiyah Lombok Hidup Menetap di Pengungsian.” Last modified 2015. https://www.rappler.com/world/asia-pacific/mengunjungipengungsi-jamaah-ahmadiyah-di-lombok.

AntaraNews. "Isu Diserang, Warga Ahmadiyah Aangkut Harta Benda ke Pengungsia," November 2010.

Arqi, Muh. Amin, Tutut Chusniyah, dan Aji Bagus Priyambodo. "Persepsi Ancaman sebagai Prediktor Intoleransi Politik terhadap Jamaah Ahmadiyah pada Jamaah Nahdlatul Wathan Pancor Lombok Timur." In Prosiding Seminar Nasional Psikologi Indigenous Indonesia 2016 "Kebhinekaan dan Masa Depan Indonesia: Peran Ilmu Sosial dalam Masyarakat". Malang: Universitas Negeri Malang, 2016.

Bilbao, Itziar Etxebarria, Amaia Eceiza Camarero, María Jesús Fuentes Rebollo, Pedro Miguel Apodaca Urquijo, dan María José Ortiz Barón. "Diferencias De Género en Emociones y En Conducta Social En La Edad Escolar." Journal for the Study of Education and Development, Infancia y Aprendizaje 26, no. 2 (2003): 147-162.

Bonasir, R. "Kenapa Ahmadiyah dianggap bukan Islam: Fakta dan Kontroversinya." BBC Indonesia, 2018.

Cohen-Almagor, Raphael. The Scope of Tolerance: Studies on the Costs of Free Expression and Freedom of The Press. London and New York: Routledge, 2006.

Crawford, Jarret T., dan Jane M. Pilanski. "The Differential Effects of Right-Wing Authoritarianism and Social Dominance Orientation on Political Intolerance.” Political Psychology 35, no. 4 (2014): 557576.

Cundiff, N. L., dan M. Komarraju. "Gender Differences in Ethnocultural Empathy and Attitudes toward Men and Women in Authority." Journal of Leadership \& Organizational Studies 15, no. 1 (2008): $5^{-15}$.

Doorn, Marjoka Van. "The Nature of Tolerance and The Social Circumstances in Which it Emerges." Current Sociology 62, no. 6 (2014): 905-927. 
Duckitt, J., dan C. G. Sibley. "Personality, Ideology, Prejudice, and Politics: A Dual-process Motivational Model." Journal of Personality and Social Psychology 78, no. 6 (2010): 1861-1893.

Fisher, Terri D., Clive M. Davis, dan William L. Yarbe. Handbook of Sexuality-Related Measures. United Kingdom: Routledge, 2013.

Gibson, J. L. "Enigmas of intolerance: Fifty years after Stouffer's Communism, Conformity, and Civil Liberties." Perspectives on Politics 4, no. 1 (2006): 21-34.

Gieling, M., J. Thijs, dan M. Verkuyten. "Voluntary and involuntary Immigrants and Adolescents' Endorsement of Multiculturalism." International Journal of Intercultural Relations 35, no. 2 (2011): 259-267.

Goudsblom, J. “Amsterdam: Amsterdam University Press.” In Macht en Verantwoordelijkheid. Essays Voor Kees Schuyt., 43-53. Amsterdam: Amsterdam University Press, 2007.

Hagendoorn, L., dan W. H. Poppe. "Consistency of Tolerance, Public Opinion on Immigrants in the Netherlands at The Turn of The Millennium.” Politics, Culture and Socialization 2, no. 4 (2012): 367-387.

Hazama, Yasushi. "Determinants of Political Tolerance: A Literature Review." Institute of Developing Economies (IDE) 288 (2011): 1-14.

Immanuel, F. W. "Namibia: Political Tolerance Towards One Namibia, One Nation."

Katnik, A. "Religion, Social Class, and Political Tolerance: A CrossNational Analysis." International Journal of Sociology 32, no. 1 (2002): 14-28.

Keuzenkamp, S. "Acceptatie van Homoseksualiteit in Nederland." In Internationale Vergelijking, Ontwikkelingen en Actuele Situatie. Den Haag: Sociaal en Cultureel Planbureau, 2011.

Kompas. "Warga NTB Masih Menolak 130 Warga JAI," 2009.

Lozano, Ana Ma, dan Itziar Etxebarria. "Tolerance of Diversity in Adolescents and Its Relationship with Self-Esteem, Empathy and The Concept of Human Being." Journal for the Study of Education and Development 30, no. 1 (2007): 109-129.

Mantara, Angga Yuni, Tutut Chusniyah, dan Muh. Amin Arqi. "Menjadi Kelompok Minoritas dalam Mayoritas: Persepsi Ancaman, Orientasi Dominasi Sosial dan Intoleransi Terhadap Jamaah Ahmadiyah.” In International Conference on Islam And Civilizations (ICIC). Jakarta: Universitas Negeri Jakarta, 2019.

Marcus, G. E., J. L. Sullivan, E. Theiss-Morse, dan S. L. Wood. With Malice toward Some: How People Make Civil Liberties Judgments. New York: Cambridge University Press, 1995.

Marcus, George E. "Ethnography in/of the world system: The emergence of multi-sited ethnography." Annual Review of Anthropology 24 (1995): 95-117.

Mummendey, Amélie, dan Michael Wenzel. "Social Discrimination and Tolerance in Intergroup Relations: Reactions to Intergroup Difference." Personality and Social Psychology Review 3, no. 2 (1999): 158-174. 
Musaropah, Umi. "Pendidikan Kebangsaan Dalam Pesantren Perspektif Abdul Wahid Hasyim.” Ulumuddin: Jurnal Ilmu-ilmu Keislaman 9, no. 1 (2019): 1-22.

Nugroho, Taufik. "Pendidikan Ideologi Al-Islam Pondok Pesantren Tenggulun Solokuro Lamongan." Ulumuddin: Jurnal Ilmu-ilmu Keislaman 9, no. 2 (2019): 97-112.

Petersen, Michael Bang, Rune Slothuus, Rune Stubager, dan Lise Togeby. "Freedom for All? The Strength and Limits of Political Tolerance." British Journal of Political Science 41, no. 3 (2011): 581-597.

Purnomo, Sigit. "Nasib Ahmadiyah, Terlantar di Negeri Sendiri." $B B C$ News. Last modified 2013. https://www.bbc.com/indonesia/berita_indonesia/2013/o8/13080 2_ahmadiyah_lombok.

Rueckert, Linda, dan Nicolette Naybar. "Gender Differences in Empathy: The Role of The Right Hemisphere." Brain and Cognitive 67 (2008): 162-167.

Scanlon, T. M. The Difficulty ofTolerance: Essays in Political Philosophy. Cambridge New York: Cambridge University Press, 2003.

Suwarta, Thomas Harming. "Sudah 11 Tahun, Pemulihan Hak Jemaah Ahmadiyah di NTB Belum Terselesaikan.” Media Indonesia, 2018.

Verkuyten, M., dan L. Slooter. "Muslim and Non-Muslim Adolescents' Reasoning about Freedom of Speech and Minority Rights." Child Development 79, no. 3 (2008): 514-528.

Verkuyten, Maykel. "Social Psychology and Multiculturalism." Social and Personality Psychology Compass 1 (2007): 280-297.

Verkuyten, Maykel, dan Luuk Slooter. "Muslim and Non-Muslim Adolescents' Reasoning About Freedom of Speech and Minority Rights." Child Development 79, no. 3 (2008): 514-528.

Wright, J. C., J. Cullum, dan N. Schwab. "The Cognitive and Affective Dimensions of Moral Conviction: Implications for Attitudinal and Behavioral Measures of Interpersonal Tolerance." Personality and Social Psychology Bulletin 34, no. 11 (2008): 1461-1476.

Yeşilada, B. A., dan P. Noordijk. "Changing Values in Turkey: Religiosity and Tolerance in Comparative Perspective." Turkish Studies 11, no. 1 (2010): 9-27. 